\title{
Respect for Equality and the Treatment of the Elderly: Declarations of Human Rights and Age-Based Rationing
}

\author{
SIMONA GIORDANO
}

\begin{abstract}
This is why Justice is often thought to be the chief of the virtues, and more sublime "or than the evening or the morning star"; and we have a proverb: In Justice is all Virtue found in Sum.
\end{abstract}

Aristotle, Nicomachean Ethics ${ }^{1}$

\section{Demographic Revolution and Related Ethical Issues}

A demographic revolution is taking place in Europe and worldwide. According to World Health Organization (WHO) estimates, the number of people aged 60 and over is growing faster than any other age group. ${ }^{2}$ This change in the population structure affects disease patterns ${ }^{3}$ and is deemed to cause an increase in the demands on healthcare systems. ${ }^{4}$ This raises concerns about the ethics of healthcare delivery (among others). What criteria should direct healthcare distribution? Is it right to meet the demands of an ageing population, to the detriment of the younger strata of population?

International organizations, such as the European Union (EU), the World Health Organization (WHO), and the United Nations (UN) have condemned any form of "ageism," including ageism in healthcare provision. ${ }^{5}$ Age-based discrimination is deemed to violate the principle of equality. Virtually all declarations, conventions, and charters on human rights stress the fundamental value of equality. Since the earliest documents, the notion of equality has been at the heart of claims of respect for fundamental human rights, such as dignity, life, and integrity. These rights apply equally "to all members of the human family." 6

In these declarations, equality is understood mainly in terms of nondiscrimination. The Charter of Fundamental Rights of the European Union, for example, reads:

Any discrimination based on any ground such as sex, race, colour, ethnic or social origin, genetic features, language, religion or belief, political or any other opinion, membership of a national minority, property, birth, disability, age or sexual orientation. (Art. 21, Nondiscrimination; my emphasis) ${ }^{7}$

Similar statements occur in virtually all other declarations and conventions, for example, in the Convention for the Protection of Human Rights and Fundamental

This paper has been written thanks to the support of the European Union, which has sponsored my project on ageism with a Postdoctoral Marie Curie Fellowship. More details on this project are available at the website http://les.man.ac.uk/simona/. I thank Prof. John Harris for our discussions on the topic and for his comments on this paper. 
Freedoms as Amended by Protocol n. 11, 4 November 1950, art. 14, Prohibition of discrimination; ${ }^{8}$ in the Convention for the Rights of the Child, 2 September 1990, Preamble; ${ }^{9}$ in the European Social Charter (Revised), 3 May 1996, Part IV, Art. E. ${ }^{10}$

However, among the countries that have signed the same declarations, public expenditure for elderly people varies significantly. ${ }^{11}$ Methods of rationing that are based on quality of life and life expectancy are employed in some countries, both at a macro- and at a microeconomic level. For example, in the United Kingdom, cost-utility approaches, health gains, quality-adjusted life years saved, and health needs analyses are increasingly being used to ration healthcare. ${ }^{12}$ These methods of rationing (although they may not be per se ageist) ${ }^{13}$ lead to age-based rationing, unless some other form of control is introduced. The U.K. Department of Health reports that "older people and their carers have experienced age-based discrimination in access to and availability of services." ${ }^{14}$

There is thus a sharp contrast between ethical theory (the ethical values on which many countries agree) and the practice of healthcare delivery. ${ }^{15}$ This contrast is in part related to the uncertainty on the meaning of equality. In part, as we shall see later, it is related to myths concerning old age. The next four sections will focus on the meaning of equality.

\section{What Is Equality?}

Equality has always been a fundamental concept in the moral universe of the Western world. In the Greek world, Justice stands out among all virtues, "fair means for distribution of goods and advantages" 16 and measure and sum of all virtues. At the etymological root of Justice there is equality. Justice, dikaiosyne, includes, in fact, in its meaning, equality (ison or isotes). ${ }^{17}$ Thus Aristotle says that "Justice is equality." 18

Our conception of what is right or wrong, or good or bad, is still inseparably linked to the notion of equality. There is something inherently "good and fashionable" in the idea of equality, ${ }^{19}$ and claims that are made under the principle of equality seem to be for this reason good.

However, it is an inherent feature of ethical principles that they may be interpreted and implemented in different and even opposite ways. For this reason, when it comes to practice, they are often of little help. Ethical principles are often "of too abstract a nature, and too universal in their scope, to enable us to ascertain by immediate application of them what we ought to do in any particular case." 20

The principle of equality is precisely one of those "very abstract" principles that can be interpreted in different ways. As Ronald Dworkin puts it, "equality is a popular but mysterious political ideal" (my emphasis). ${ }^{21}$

The fact that the notion of equality may be interpreted in different ways has historically had important implications in political philosophy (e.g., relating to the role and the objectives of a democratic system-formal and substantive democracy). Nearly 30 years before the French Revolution offered one of the most important declarations of "equality" of all times (1789), Rousseau pointed out that the notion of equality may have different meanings, and that it is important to clarify what we mean by equality. For example, saying that "men are equal" does not of course mean that they are "physically" equal ("in 
strength or intelligence"), but that they are "morally" equal (in rights and by convention). ${ }^{22}$

In this way, Rousseau not only provided one of the first articulations of the formal conception of equality, how we mean it today in most democratic systems, but also responded to one of the oldest and most compelling criticisms of equalitarianism, the one from Plato. In the Republic, Plato argued that not all men are equal, and therefore they cannot and should not be treated as equals. ${ }^{23}$ Respect for equality does not demand equal distribution among unequals. In The Laws, Plato wrote: "[W]hen equality is given to unequals the result is inequality." ${ }^{24}$ Men should be treated unequally, as they are unequal. (We shall see later how a similar argument is nowadays used in support of age-based rationing.)

Rousseau showed that men do not need to be "equal" in all senses (physically equal, e.g.) to deserve equal respect and consideration, and that the principle of equality of course applies equally to unequal people, because despite their differences in strength, intelligence, and other arbitrary features, people are still morally equal. Therefore, they equally deserve to have their human rights respected, independent of their different features.

In the field of healthcare distribution, the broad and abstract nature of the principle of equality, and the absence of specifications (equality of what? What should we give to people in order to treat them according to equality? How should an equitable distribution be understood?) has led to problems of interpretation of the principle and to different opinions as to its applications. People agree that equality should be respected, but it is unclear how equality should be understood and what "respect for equality" involves.

We shall now see how equality can be understood (or misunderstood) and the consequences that this may have on the issue of healthcare distribution.

\section{A (Mis) Interpretation of Equality}

According to some people, equality does not require us to treat people equally. Plato, as we have seen above, proposed a similar critique of equalitarianism. In the field of healthcare, this implies that claims coming from different patients or groups of patients have a different moral weight. Older patients, for example, have already had a long life, presumably they have shorter life expectancy, and they will not benefit from healthcare as much as younger patients, in terms of gains in quality and quantity of life. Because the old and the young differ in these (and maybe in other) important ways, treating them differently is not treating them unequally. ${ }^{25}$

This argument has taken two general forms. According to some, healthcare system should try to equalize the length of life of the population (fair innings argument). ${ }^{26}$ Older people should be given lower priority because they have already lived a long life, and other people should be given the opportunity to live as much.

According to others, healthcare systems should not primarily focus on how long a person has already lived, but on the quality and quantity of life left to live. The underlying idea here is that healthcare systems should distribute the greatest amount of quality and quantity of life among the largest number of people. The philosophy behind this idea is utilitarianism in its classic form: The right action is the one that promotes the greatest happiness for the largest 
number of people. ${ }^{27}$ A certain conception of equality also stands behind this argument. Healthcare systems should maximize people's quality and quantity of life and should try to ensure that all people overall will benefit from this policy. To give equal weight to the claims coming from those with "below average capacity to benefit" ${ }^{28}$ will lead to a reduction in health gains in the population as a whole. From this point of view, resources are better employed if given to patients with "positive" quality of life and life expectancy. ${ }^{29}$

The two arguments outlined above are conceptually different, and may result in different distributive policies. ${ }^{30}$ However, normally, they both share a common point: Lower priority should be given to the older patient. They both reflect a strong intuition that many people seem to have, that if a doctor is in the invidious situation of having to make a choice between rescuing a 20-yearold and a 90-year-old person, she should prioritize the young, because the 90-year-old has already lived a long life or because she will die soon anyway or because her quality of life will not be significantly improved.

There have been many further articulations of these arguments. Some have, for example, suggested that some trade-off should be made between the assessment of outcome of healthcare provision and the patients' medical needs. ${ }^{31}$ Others have suggested some trade-off between quality of life, life expectancy, and already lived life. ${ }^{32}$ For the purposes of this paper, I shall not analyze in detail these various formulations. I shall only consider the two general arguments outlined above and the concept of equality/equalization that stands behind them.

From this point of view, for the healthcare system to implement the principle of equality is to try to give everybody a similar positive amount of quality and quantity of life. To give a little extra quality and quantity of life to some people to the detriment to those who may benefit more from treatment is unjust.

\section{The Trouble with This Interpretation of Equality}

The idea that healthcare systems should try to equalize (or maximize) ${ }^{33}$ people's length and quality of life seems, at first sight, to correspond with the idea that most healthcare professionals would have of themselves: Their duty is to do the "most good." 34 The underlying assumption here is that the objective of healthcare is enhancing health, an assumption which seems, at first sight, undisputable, and which has led economists and philosophers to articulate cost effectiveness and cost utility analyses to be applied to healthcare. ${ }^{35}$

However a number of persuasive objections have been made against this assumption and related methods of rationing, ${ }^{36}$ and others can be made as well. One of the most important objections is that methods of rationing based on quality and quantity of life seem to reflect what people want, but in fact they are not. Of course everybody would want for himself or herself the best chance of the longest and best quality of life when they apply for treatment. The outcome of medical interventions in terms of quality and quantity of life is certainly important to each of us. From this, however, it does not follow that everybody would want physicians to distribute their services first to those who will benefit most from treatment or who are likely to have the longest and best quality of life after treatment and only after to those whose quality of life, in the physicians' views, is going to be poorer than that of other applicants. 
In other words, whereas it may be assumed that each of us would like the best and longest life that is attainable, this does not imply that we would like to delegate judgments about the worth of our life to healthcare professionals. It does not follow from the fact that I want the treatment that would secure for me the longest life expectancy of the best quality, that I also want that someone else who can get better quality life expectancy from treatment should have priority. Methods of rationing that are based on quantity and quality of life seem at first sight to reflect what people want, but in fact do not. What matters to people is not "the number of healthy life years the world contains," 37 but the number of healthy years that they or people they care about will have.

We also need to consider the practical implications of this interpretation of equality. This interpretation (equality of length and quality of life) may lead to patient selection on the basis of their prognosis (life expectancy, quality of life, and therefore age). The outcome could be properly called a dictatorship of the healthcare system: In this system, professionals would decide which lives are worth living.

Having examined the problems with this interpretation of equality, we shall now consider a different interpretation of the principle.

\section{How Equality Should Be Understood}

According to another argument, equality requires equal respect for each person's preference to live the longest and best life that is attainable. So, when it is said that healthcare systems should treat people according to equality-or should not discriminate unfairly-what is meant is that healthcare systems should treat each of these preferences equally, that is, they should give equal moral weight to each of these preferences, independent of contingent factors, such as the person's quality of life or age. ${ }^{38}$

The underlying assumption here is that each person has equal value, whether or not they are young, old, or disabled. Because each person's life has equal value, each person's preference to continue to live counts equally, even if the quality of life of the claimant appears to be "lower" than that of other claimants, or even if other people believe it is not worthwhile for that person to apply for treatment. Any similar preference to live, or to live longer or in better health, has equal moral weight. ${ }^{39}$ That claim expresses the value that that person attaches to her life, and that preference is equally strong, however good or long her life is or turns out to be. Respect for equality is respect for this preference. It is respect for the person's life, for the value that she attaches to her own life. Under this perspective, the preference that each person has to continue to live counts equally, however long her life has already been or is going to be, and whatever its quality, thus far as the person believes that life (her own life) is worth living. This does not of course mean that "one is entitled to have their own needs met whatever the cost," 40 but that "each is entitled to equal consideration of their needs and that needs do not vary in proportion to the chance of their being satisfied." 41

It seems that this interpretation of equality is consistent with the recommendations of the WHO, the EU, and the UN. The major international organizations increasingly stress the equal rights of elderly people to access medical care. Human rights, such as the right to life, to medical care, and to respect for dignity, apply equally to all members of the human family, and older people are an 
important part of the human family. The argument that healthcare distribution should be based on patients' quality and quantity of life and that elderly people have a lower entitlement to have their human rights respected is based on a misunderstanding of equality, one that leads to violation of the fundamental human rights and universal ethical principles stated in declarations, conventions, and charters of human rights.

Besides a misinterpretation of the notion of equality, a number of myths about old age may induce someone to believe that age-based rationing may be acceptable, and may also explain why different countries have adopted different distributive policies. Old age is often perceived as an age of dependency and frailty, and the capacity of the older person to benefit from healthcare delivery or to their capacity to reciprocate the support that they receive from society are often misconceived. The next sections will show that there is no empirical ground nor any theoretical ground for advocating age-based rationing of healthcare resources.

\section{"A Gray World" Will Lead Healthcare Systems to Bankruptcy}

One of the worries relating to the growing proportion of elderly people in industrialized countries is that healthcare costs will spiral out of control. Some may fear that this may have a disastrous impact on the society as a whole.

Any similar worry is based on a misconception of the reasons for escalating healthcare costs in ageing societies. We have seen at the beginning that the growing presence of elderly people represents a challenge for healthcare systems. However, increases in healthcare costs are not directly related to old age.

Research in countries with aged populations has shown that ageing per se is not likely to lead to health care costs spiralling out of control ... According to OECD data, the major causes of escalating health care costs are related to ... [i]nefficiencies in care delivery, building too many hospitals, payment systems that encourage long hospital stays, excessive numbers of medical interventions and the inappropriate use of high cost technologies.... For example, in the United States and other OECD countries, new technologies were sometimes rapidly introduced and used where alternative and less expensive procedures already existed, and for which the marginal effectiveness was relatively low. ${ }^{42}$

Moreover, what is costly is not "old age," but disability and poor health. Disability and poor health are often linked to old age, but do not depend on age. It is demonstrated that appropriate prevention would allow people to age in better health, and consequently medical spending may not increase as rapidly as is sometimes thought. ${ }^{43}$

\section{Older People Do Not Offer Valuable Contributions to Society}

Old age is often presented as a season of dependency and frailty, one in which the person has nothing more to offer or nothing valuable to offer, and it may be argued that we cannot afford the rescue of people who will not offer valuable contributions to society. The WHO has, however, pointed out that the belief that older people do not offer valuable contributions to the labor market and to 
the society as a whole ${ }^{44}$ is simply false. Many older people continue to work either in formal or in informal labor sectors. ${ }^{45}$ The elderly often take responsibility for household management and childcare, thus allowing younger adults to work outside the house; in this way, the elderly actively contribute to the labor market. Moreover, older people often offer work in voluntary sectors, acting as volunteers in schools, communities, religious institutions, and business, health, and political organizations. Many elderly people, thus, prove to be a precious resource for the fabric of our society and a healthy ageing population, far from representing a burden for the society, would advantage the overall economy.

\section{Age Affects the Outcome of Medical Procedures}

Some people may believe that it is appropriate to withdraw some medical procedures from people above a certain age because these procedures would have little benefit for them. Some studies show that this assumption is often mistaken. It is reported for example that the outcome of intensive care and surgery for those over 65 differs very little from the outcome of younger patients. This may be linked to selection policies, ${ }^{46}$ but at least demonstrates that age in itself does not mean that these therapies are all no good for older people.

\section{The Good That May Be Done to the Elderly Is Sometimes Not Enough to Balance the Costs of Healthcare Delivery}

Some people may believe that allocating some healthcare resources to the elderly may not be compensated by appropriate gain (even if the patient thinks otherwise). The good done to the older person is not enough to compensate medical costs. Harry Lesser provided an important objection to this argument. ${ }^{47}$ He pointed out that, whereas there can be good reasons for not resuscitating certain patients if their death is imminent anyway or if they would be resuscitated to an intolerable existence, there is no age above which this is necessarily the case. Therefore a blanket policy of not resuscitating or not treating patients above a certain age cannot be right. It is appropriate to ask "Can the patient benefit from treatment?", and the effects of ageing (which are different for different people) may be relevant to this question. However, chronological age per se, is not relevant. This, as Lesser clarifies, does not mean that we should do everything just because we feel we must do something. "But we should not pretend that easing or extending a person's final years, or months, or even days, is 'doing no good'!" 48

\section{Discrimination or Not?}

The misconceptions of old age discussed above reinforce the idea that treating elderly people unequally is not a violation of equality. Elderly people would thus not be discriminated against but just treated appropriately, according to their different status or condition.

It should be noticed that virtually always, in support of unjust treatment of a group of people, it has been claimed that the group discriminated against was just being treated according to their "different status" or condition (and there- 
fore appropriately-or justly). All forms of discrimination have always been "justified" on the basis of the presumed inequality between the discriminating group and the one discriminated against (where inequality means that the group discriminated against has less worth or value or importance than the discriminating group). In the vast majority of cases, claims that one group of people has less worth or value than another normally have no support other than the strength with which they are made, and most likely rest on lack of recognition of the value, or worth, of a group of people (and not on the actual lack of value or worth of that group). Of course, a public policy that is based on the ignorance of the merits, the contribution, and the worth of a group of citizens can neither be accepted nor recommended.

\section{Conclusions}

The unprecedented increase in the older population that is taking place in industrialized countries determines changes in disease patterns and consequently in the demands for healthcare resources. Different distributive policies are adopted in different countries, and age-based rationing is sometimes defended in philosophical debates. This paper has assessed whether age-based rationing may be considered coherent with ethical frameworks and universal principles expressed in the most prominent documents on human rights subscribed to in Europe and worldwide. A critical analysis of these principles has been provided and the reasons for dissent have been explored. The conclusion of this analysis is that no age-based rationing may be considered coherent with universal ethical principles, and that there is no valid reason, either theoretical or empirical, to deny the elderly full membership to the human family.

\section{Notes}

1. Aristotle. Nicomachean Ethics. Rackham H, transl. Cambridge, Mass.: Harvard University Press; 1968 at p. 259.

2. WHO. Active Ageing, a Policy Framework. WHO/NMH/NPH/02.8. Geneva: WHO; 2002; Kalache A, Keller I. The greying world: A challenge for the twenty-first century. Science Progress 2000; 83(1):33-54.

3. WHO. Life in the 21st Century: A Vision for All (World Health Report). Geneva: WHO; 1998.

4. See note 2, WHO 2002:17.

5. See note 2, WHO 2002:40, 46, 50. See also Brasilia Declaration on Ageing, WHO, 1-3 July 1996. Available at http://www.oneworld.org/helpage/info/brasilia.html; UN International Year of Older Persons, 1999. Available at http://www.un.org/esa/socdev/iyop/.

6. Universal Declaration of Human Rights (Preamble); 1948. Available at http://www.un.org/ Overview/rights.html; Council of Europe. Convention for the Protection of Human Rights and Dignity of the Human Being with Regard to the Application of Biology and Medicine: Convention on Human Rights and Biomedicine. Oviedo 4 April 1997. Available at http://conventions.coe.int/ treaty/en/treaties/html/164.htm; United Nations. Convention on Elimination of All Forms of Discrimination against Women, Sep 3 1981. Available at http://www.un.org/womenwatch/daw/ cedaw/.

7. Available at http://www.europarl.eu.int/charter/default_en.htm.

8. Available at www.echr.coe.int/Convention/webConvenENG.pdf.

9. Available at http://www.unhchr.ch/html/menu3/b/k2crc.htm.

10. Available at http://conventions.coe.int/Treaty/EN/Treaties/Html/163.htm.

11. Jacobzone S, Oxley H. Ageing and Health Care Costs. Available at http://fesportal.fes.de/pls/ portal30/docs/FOLDER/IPG/IPG1_2002/ARTJACOBZONE.HTM. 
12. Department of Health. Purchasing for Patients. London: HMSO; 1991; Department of Health. Health of the Nation: a Strategy for Health in England. London: HMSO; 1992.

13. Schwappach DLB. Resource allocation, social values and the QALY: A review of the debate and empirical evidence. Health Expectations 2002;5 at p. 211.

14. Department of Health. National Service Framework for Older People, Executive Summary. London: Department of Health; March 2001:6. Available at www.doh.gov.uk/nsf/olderpeople.htm; The Department of Health published a new report in 2003. See Department of Health. National Service Framework for Older People. A Report of Progress and Future Challenges. London: Department of Health; March 2003.

15. Kalish WD, Aman T, Buchele AL. Social and health policies in OECD countries: A survey of current programmes and recent developments. OECD Working Papers. Paris: OECD; 1998 at p. 7.1.

16. Reale G, Antiseri D. Il Pensiero Occidentale Dalle Origini ad Oggi. Brescia: La Scuola; 1983 at p. 151.

17. Vlastos G. Justice and equality. In: Waldron J, ed. Theories of Rights. Oxford: Oxford University Press; 1984 at p. 41.

18. See note 1, Aristotle 1968: Book V 1131a 13.

19. Raz J. The Morality of Freedom. Oxford: Clarendon; 1988 at pp. 227-9.

20. Schneewind JB. Sidgwick's Ethics and Victorian Moral Philosophy. Oxford: Oxford University Press; 1977 at p. 289.

21. Dworkin R. What is equality? Part 1, Equality of welfare. Philosophy and Public Affairs 1981;10 at p. 185.

22. Rousseau JJ. Du Contract Social, ou Principes du Droit Politique. Amsterdam: Chez Rey MM; 1972.

23. Plato. Republic. Waterfield R, ed. Oxford: Oxford Paperbacks; 1998 at p. 588.

24. Plato. The Laws. Taylor AE, trans. London: Dent; 1960 at p. 757a.

25. Murray CJ. Quantifying the burden of disease: The technical basis for disability-adjusted life years. Bulletin of the World Health Organisation 1994;72 at pp. 429-45.

26. See note 13, Schwappach 2002 at pp. 210-22. For a discussion of the "fair innings argument" see Harris J. The Value of Life. London: Routledge \& Kegan Paul; 1985:chap. 30. This is known as the absolute formulation of the fair innings argument. Williams has articulated a relative formulation of the fair innings argument, in which not only the length of life already lived of the competitors is considered, but also their capacity to benefit from treatment. Williams A. Intergenerational equity: An exploration of the "fair innings" argument. Health Economics 1997;6:117-32.

27. Bentham J. Introduction to the Principles of Morals and Legislation. Oxford: Oxford University Press; [1789] 1996:chap. 1.

28. Dowie J. Analysing health outcomes. Journal of Medical Ethics 2001;27(4):245-50. Online version p. 7.

29. Harris J. What is the good of health care. Bioethics 1996;10(4):269-91; Callahan D. Allocating health care resources. Hasting Center Report 1988;18:14-20.

30. For easiness, I am here bringing together these two different arguments: one concerns the equalization of people's welfare. The other concerns the maximization of people's welfare. I am bringing these arguments together because generally they both support age-based distribution, which is the topic of this paper. From the point of view of equalization everybody should be entitled to their fair share of health and length of life. Age matters because of the amount of already lived life. An old person should be given lower priority because she has already lived a long and maybe enjoyable life, and younger people should be given the same opportunity. From the point of view of maximization of health and life expectancy, the issue of the relevance of age is derived from the issue of the relevance of life expectancy and quality of life. If life expectancy and quality of life matter in healthcare distribution, then age matters.

31. Hirst MA. Multidimensional representation of disablement-A quantitative approach. In: Baldwin S, Godfrey C, Propper C, eds. Quality of Life. London/New York: Routledge; 1990. Quoted in Jenkins M. Ethics and economics in community care. Critical Social Policy 2001;21(1):81-102.

32. See note 26, Williams 1997:117-32.

33. See note 30 .

34. See note 29, Harris 1996:270.

35. One of the first formulations of this idea was made by Torrance. See Torrance GW. Measurement of health state utilities for economic appraisal. Journal of Health Economics 1976;5(1):1-30. 


\section{Simona Giordano}

See also Rosser RM, Kind P. A scale of valuation of states of illness: Is there a social consensus? International Journal of Epidemiology 1978;13:117-23.

36. Harris J. What the principal objective of the NHS should really be. BMJ 1997;314:669-72. Reprinted in New B, ed. Rationing: Talk and action in health care. London: BMJ Publishing Group; 1997:100-6; Harris J, Giordano S. Pari opportunità nella distribuzione delle risorse sanitarie. Keiron 1999; Jun.:26-8.

37. See note 29, Harris 1996:275.

38. Harris J. Are moral claims age-relative? In: Tallis R, ed. Increasing Longevity: Medical, Social and Political Implications. London: The Royal College of Physicians, London; 1998:61-70; Harris J. Cardiac surgery in the elderly-A commentary. Heart: Official Journal of the British Cardiac Society 1999;82(2):119-21; Harris J. QALYfying the value of life. Journal of Medical Ethics 1987:117-23. Reprinted in Downie RS, ed. Medical Ethics. Aldershot: Dartmouth; 1996; Harris J. Unprincipled QALYs. Journal of Medical Ethics 1991;17(4):185-8.

39. This is not to say that healthcare systems should offer whatever services people may ask to lengthen or improve their lives, independent of their medical needs. This is to say, on the contrary, that healthcare systems should treat similar claims in an equal way. We are not discussing cases in which extra services are denied because the quality of life of the claimant is "too good" already, but precisely the opposite; we are discussing cases in which medical services are denied because the quality of life of the claimant is believed to be "too low." Elderly people and their caregivers have experienced discrimination in the provision of treatments that are not extravagant, such as hip replacements, cataract surgery, dentistry, or referral to specialists. See note 14, Department of Health 2001 at p. 6.

40. See note 29, Harris 1996:290.

41. See note 29, Harris 1996:290.

42. See note 2, WHO 2002:42. This provides us with grounds to believe that rationing between patients or groups of patients is not the only possible response to the disproportion between demands and healthcare resources. Appropriate interventions at the level of prevention and public healthcare policy will certainly contribute significantly to correction of such an imbalance, in coherence with ethical frameworks accepted in Europe and worldwide.

43. See note 2, WHO 2002:17.

44. Nilstum T, Ohlsson R. Should health care be rationed by age? Scandinavian Journal of Social Medicine 1995;23(2):81-4.

45. See note 2, WHO 2002:9.

46. Jennett B. The elderly and high technology therapies. In: Wells N, Freer C, eds. The Ageing Population: Burden or Challenge? London: MacMillan Press, 1988:177-90.

47. Lesser AH. Justice and the principle of triage. In: Lesser AH, ed. Ageing, Autonomy and Resources. Aldershot: Ashgate; 1999.

48. See note 47, Lesser 1999:211. 